\title{
2nd Nazareth Conference on Dental Public Health
}

$\mathrm{T}$ he 2nd Nazareth Conference on Dental Public Health was held on 18-19 May 2017 at the Golden Crown Hotel, Nazareth, Israel, and opened by MK Harav Yaakov Litzman, Minister of Health.

Having attended the first conference in 2014, I was looking forward to returning for the second conference in 2017. This year again about 500 delegates registered to hear both Israeli and international speakers. Presentations were broad ranging from embryonic stem cell biology by Professor Jakub Hanna, of the Weizmann Institute, Israel, to a stimulating presentation on future influences on dental practice viability by Dr Marc B. Cooper, The Mastery Company, US. Professor Ismail Amid gave two stimulating talks focusing on the outcomes of comprehensive dental care.

The content was of interest to dental public health practitioners as well as to general dentists, ancillary staff and managers. The stated objective of relating theory to practice was well met by presentations in English and Hebrew, with simultaneous translation to both languages and Arabic.
The Golden Crown Hotel is located high on Mount Precipice, with a magnificent view of the Jezreel Valley, the perfect location for a gala dinner held on the first evening. This location provides easy access to the many historical and religious sites in Nazareth and beyond, with much to interest accompanying persons.

The conference included poster presentations and recognised the significant contribution of the late Professor Aubrey Sheiham to dental public health with the first Aubrey Sheiham Intern Presentation Contest which is open to all interns and trainee specialists in dental public health worldwide. Dr Aflalo from the Dental Health Division of the Ministry and Dr Yablon from the Community Dental Health Department of the Faculty of Dental Medicine of Hadassah both won the first contest.

The next conference will be held in 2020 at the same location and again, I hope to attend. The conference website is: http:// www.nazareth-conference.com. Updates and further information are also available on the conference's Facebook pages.

By Michael J. Fleetwood, Canberra, Australia

\section{New BDA Northern Ireland Director}

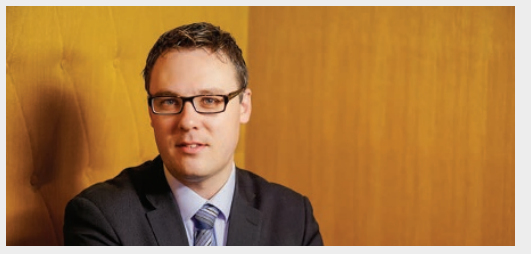

The British Dental Association (BDA) has announced Tristen Kelso as its new Northern Ireland Director, following the recent retirement of Claudette Christie.

Tristen joins the BDA from leading public affairs agency Stratagem, where he served as health lead for four years, overseeing accounts ranging from Cancer Focus NI and the British Heart Foundation, to community providers such as Specsavers.

He has also served as a political advisor to an MEP, and has led on policy for the Integrated Education Fund and The Ulster Farmers Union. He was due to start at the BDA on 4 September.

Tristen said: 'I am delighted to join the BDA as its Northern Ireland Director. While we do not yet have a government at Stormont, we do have unfinished business on contracts and an oral health strategy that is need of an urgent update. My commitment is to offer the strongest possible voice for dentists in Northern Ireland'.

\section{BOOK REVIEW}

\begin{tabular}{|c|c|}
\hline Tintreanthedition & McCRACKEN'S REMOVABLE PARTIAL \\
\hline \multirow{3}{*}{$\begin{array}{l}\text { REMOVABLE } \\
\text { PARTIAL } \\
\text { PROSTHODONTICS }\end{array}$} & PROSTHODONTICS, 13TH EDITION \\
\hline & Alan B. Carr and David T. Brown \\
\hline & Elsevier, 2015 \\
\hline 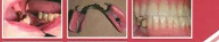 & price $f 92.99$ pp392 \\
\hline S. 18 & ISBN 9780323339902 \\
\hline
\end{tabular}

McCracken's removable partial prosthodontics has long been an influential and informative resource for clinicians and students of all levels. This latest edition, the thirteenth, does not disappoint.

The book is divided into three logically sequenced sections. The first of which, 'general concepts/treatment planning', containing 12 chapters, provides the reader with a clear understanding of epidemiology, terminology, classifications, and partial denture components, paving the way to tackle the often poorly understood partial denture design topic in a sensible manor.

The second of the three sections incorporates clinical and laboratory techniques, bringing the reader through patient assessment, clinical stages and materials in nine chapters. A step-by-step approach is described, tying it all together with associated laboratory stages involved, which can all too often be forgotten. This section contains a very useful chapter on support for the distal extension denture base and how to improve functional support through impression techniques. The final section, 'maintenance', contains a very useful component covering repairs and additions to removal partial dentures.

Throughout, the text is beautifully accompanied by clinical photographs which themselves are usefully and informatively annotated. Shaded sections are jotted throughout the book, which are aimed for the more 'advanced' clinician. I personally found these useful and informative and would encourage practitioners of all stages to read them, not just those who are 'advanced'.

As with previous editions of this text, I would describe this book as a comprehensive text for anyone wishing to gain a greater understanding of removable partial dentures and in particular their design.

W. Keys 